\title{
What is wrong with this picture?
}

\author{
Miranda Robertson ${ }^{1, *}$
}

When we first published our iconic image (Figure 1), devised on the fusion of BMC Biology with Journal of Biology in 2010 [1], we anticipated outraged objections from the microbial research community (among others) with a disclaimer acknowledging an element of artistic licence in the allocation of space per phylum (see legend to Figure 1, reproduced from [1]), successfully disarming Jonathan Eisen (http://phylogenomics.blogspot.co.uk/ 2011/09/no-award-to-give-out-but-here-are-some.html) when he justly rose to the attack last year, and so far avoiding aggrieved comment on the underrepresentation of beetles.

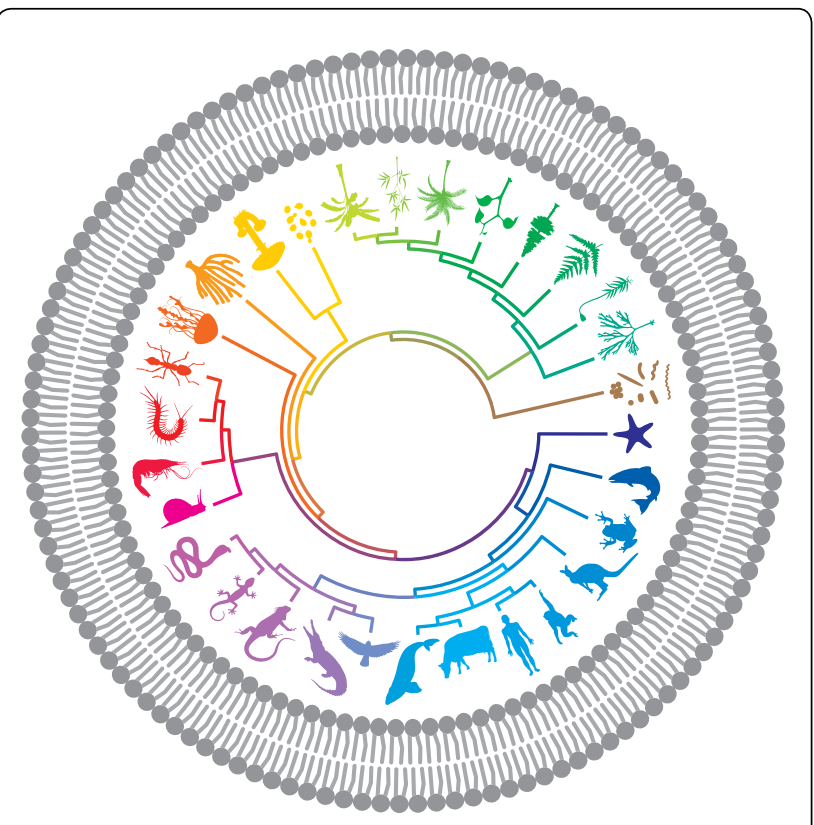

Figure 1. The BMC Biology image. The problem of representing all of biology is encapsulated in the image we have devised as an emblem for the fusion journal. Our protocellular lipid bilayer surrounding a circular representation of a rootless phylogenetic tree omits explicit reference to molecular and cellular structure and much else; and purists will find fault with the phylogeny. We must ask you all to settle for the Gestalt.

*Miranda Robertson bmcbiologyeditorial@biomedcentral.com 'BMC Biology, BioMed Central, 236 Gray's Inn Road, London WC1X 8HL, UK
We had reckoned however without the fluidity of phylogenetic classification. With the welcome addition of Peter Holland to our Editorial Board this month, we learn that according to the most recent version of the dendrogram we have two of the representative organisms on our tree the wrong way round. Before we change it, it would clearly be judicious to check whether other revisions are required; so we have left it as it is, and invite expert input as we research the literature for recent seismic changes in our understanding of phylogenetic relationships consequent on more sophisticated analysis and deeper sequencing of more genomes.

A brief inspection of our own recent publications suggests, reassuringly, that we shall be protected from much revision by the low resolution of our tree and selective illustration of its branches. A recent paper in $B M C$ Biology reflecting a current skirmish on the placing of turtles [2] leaves our image unaffected not only because it affirms their placing among the archosaurs [3], but because turtles do not appear on our tree at all (see the addition to the relevant branch in Figure 2). A recent refinement of the carnivore supertree [4] is simply ignored by our tree which has no carnivores on it; and had microsporidia not settled down as a consensus fungal taxon [5], they could have bounced from one major branch to another of the phylogenetic tree with absolutely no impact on the BMC Biology version, whose singlecelled fungal blobs are indistinguishable from the protozoal blobs several branches away.

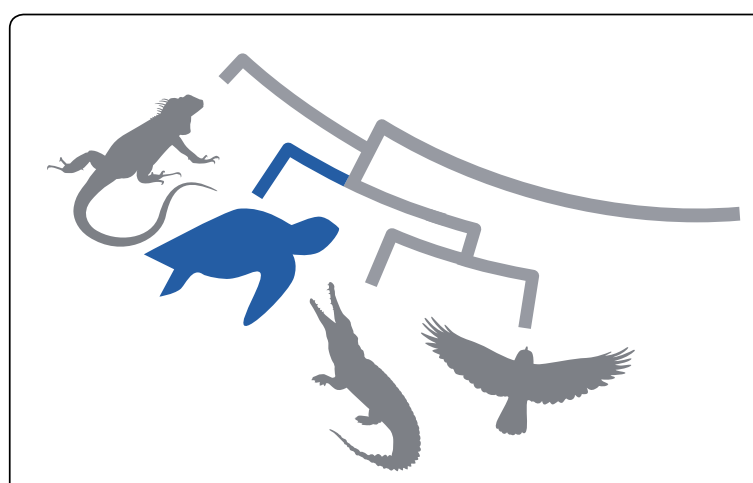

Figure 2. The position of turtles on the phylogenetic tree. 
We shall be publishing a corrected image soon. Suggested adjustments should be supported by references.

Published: 3 September 2012

\section{References}

1. Robertson M: Plus ça change. BMC Biology 2010, 8:44

2. Chiari Y, Cahais M, Galtier N, DelsuC F: Phylogenomic analyses support the position of turtles as the sister group of birds and crocodiles. BMC Biology 2012, 10:65

3. Hedges SB: Amniote phylogeny and the position of turtles. BMC Biology $2012,10: 64$
4. Nyakatura K, Bininda-Emonds ORP: Updating the evolutionary history of Carnivora (Mammalia): a new species-level supertree complete with divergence time estimates. BMC Biology 2012, 10:12

5. Capella-Gutiérrez S, Marcet-Houben M, Gabaldón T: Phylogenomics supports microsporidia as the earliest diverging clade of sequenced fungi. BMC Biology 2012, 10:47

doi:10.1186/1741-7007-10-76

Cite this article as: Robertson $\mathrm{M}$ : What is wrong with this picture?. BMC Biology 2012, 10:76. 